\title{
An analysis of the smartphone dictionary app market
}

\author{
Christopher Winestock • Young-kuk Jeong
}

Received: 5 January 2014 / Accepted: 18 April 2014/Published online: 20 April 2014

(C) Springer Berlin Heidelberg 2014

\begin{abstract}
In this paper, an analysis of the smartphone dictionary app market is presented. The three types of business models used between dictionary publishers and software developers are listed as well as their advantages and disadvantages. Next, the Apple App Store and Google Play, the main online stores selling dictionary apps, are described in terms of their market share and revenue. Although the Apple App Store is currently in the lead, Google Play is catching up very quickly, particularly in Japan and South Korea. An estimate of the dictionary market as a percentage of all apps is given next. In both the Apple App Store and Google Play, dictionaries account for $0.22-1.21 \%$ of the app store income, depending on the country. Dictionary apps, however, do not appear in the top 200 grossing apps of any app store and hence are not great money earners in the league of games and productivity apps. The number of free and paid dictionary apps in Google Play and the Apple App Store is next calculated and conclusions about the differences in quality and price of dictionaries in the two stores are explained. By studying the features of top grossing apps, an attempt is made to identify the characteristics of top selling dictionary apps. Other business models of dictionary apps, such as freemiums and in-app purchases, are explored and finally the future of the dictionary app market in light of competing products is described.
\end{abstract}

Keywords App · App store · Dictionary · Market survey

Communicated by Yukio Tono.

C. Winestock $(\bowtie)$

DIOTEK Co., Ltd, 14F, Digital-ro 9-gil 65, Geumcheon-gu, Seoul 153-713, South Korea

e-mail: c_winestock@diotek.co.kr

Y. Jeong

International Graduate School of English, Yangjae-daero 81-gil 17,

Gangdong-gu, Seoul 134-847, South Korea

e-mail: young@igse.ac.kr 


\section{Introduction}

The advent of mobile phones, tablets and their associated app stores has given rise to a large range of free and paid dictionary apps for mobile devices. As sales from the print dictionary industry decline, publishers are trying hard to make up for the loss in revenue using the income from dictionary app sales, particularly over the last 3 years. Software developers are also scrambling to license premium dictionaries from well-known publishers so that they can profit from the smartphone app boom.

To provide a better understanding of the dictionary app market and business models, an analysis of the current state of the market is provided. The focus is on apps containing premium dictionaries from well-known publishing houses, not on the hundreds of apps containing unbranded, often non-professionally compiled word lists.

First, the underlying business model of dictionary apps, i.e., revenue models, will be explained. Next, the relative importance of the two major app stores Apple app store and Google Play will be examined in terms of revenue, number of dictionaries and app pricing. The language coverage of available dictionary apps is subsequently covered, as well as the characteristics of high-grossing dictionary apps.

Finally, new business models involving freemiums and in-app purchases are analyzed as well as the major competitors of dictionary apps.

\section{App business model}

As dictionary publishers have little experience in app software development, they work together with an app software developer to create a dictionary app, which is then uploaded onto an app store. Broadly speaking, there are three models which describe the way in which the publisher and developer cooperate, share costs and distribute store revenue.

\subsection{Model A}

This first business model is adopted when the publisher wishes to invest little time, effort and money in creating the app. The publisher may not have the human resources and know-how to design dictionary apps and so leaves all decisions completely up to the software developer. The publisher licenses the dictionary content to an app developer, who then takes complete control of the app. The developer makes all decisions regarding the app's design, functions, the marketing of the app and the app store registration and management. The developer is also the owner of the app.

A major disadvantage of this approach is that software developers have little experience in terms of how dictionary content should best be utilized and displayed or how dictionaries should be marketed, so the app design, app store description and app functions implemented are often suboptimal. Since app developers lack knowledge on ways to enhance dictionary content and improve the user experience 
of dictionary lookups, developers focus more on reducing the cost of development as a way to increase profitability. The most basic apps, for example, only support basic headword search and entries are displayed simply as a block of text with minimal styling or formatting.

In terms of profit sharing, the publisher often asks for between 40 and $60 \%$ of the store revenue, after the $30 \%$ app store fee has been deducted. Sometimes publishers may also ask the developer to provide an initial lump sum to license the data. Rarely, publishers may ask the developer to guarantee a minimum level of revenue regardless of the income from app sales.

\subsection{Model B}

The second app business model is adopted when publishers wish to invest more time, effort and money in the active design and development of the app. The publisher owns the app, determines to a large extent the app design, functions and marketing. He or she is also responsible for registering and managing the app on the app store. The developer merely implements the design specifications prepared by the publisher. This model has the advantage that publishers can make use of their expertise in lexicography; however, the development time and cost often end up being higher as the publisher often asks for extra, more complex linguistic features to be implemented. The daily rankings of high-grossing dictionary apps do not show evidence that more sophisticated dictionary apps sell better than simple apps, so the time and money invested in enhancing an app will probably not be rewarded by better sales.

The publisher may pay the developer a set fee for the entire development of the app with no revenue sharing. To reduce the development costs, the publisher may agree to share the revenue, e.g., $20 \%$ of store profits going to the developer in return for a reduced development fee. To reduce the upfront investment entirely, a 40$60 \%$ revenue sharing agreement with the developer might be made with no lump app development fee at all.

\subsection{Model C}

The final business model is a B2B business model. In this model, a mobile device manufacturer pays a software company to develop a dictionary app using dictionary content which the software company has licensed from a publisher. Alternatively, the manufacturer may contact the dictionary publisher directly and ask them to provide their dictionary data in a standardized format so that the data can be easily integrated into the manufacturer's own proprietary dictionary viewing software. The app is then provided free to users of the phone either as a pre-installed app, a downloadable resource or a free app on an app store. In general, the publisher or software developer maintains ownership of the app and simply licenses the dictionary app software to the device maker. The fee paid to the software company is commonly based on an estimate of the number of devices and in which countries 
the dictionary app will be made available. Alternatively, the fee may be based solely on development cost.

\section{App stores}

The most important two online stores from which dictionary apps can be purchased are the Apple App Store operated by Apple, and Google Play operated by Google. The Apple App Store sells iPhone and iPad-compatible apps, and Google Play sells Android compatible apps. Note that there are other app stores such as Amazon (www.amazon.com), Blackberry World (appworld.blackberry.com), Windows Marketplace (www.windowsphone.com/en-us/store) and the Nokia Store (store. ovi.com); however, their contribution to overall revenue is very minor and hence will not be discussed further.

The Apple App Store currently yields the highest revenue for smartphone apps. The gap between it and Google Play, however, is closing rapidly. According to Distimo's 2013 Year in Review (Schoger 2013), the total global revenue for the top 200 grossing apps on the Apple app store on an average day in November 2013 was USD \$18 million dollars and on Google Play USD\$12 million. Hence, the Apple App Store revenue was $50 \%$ higher than Google Play in November. Android is, however, quickly gaining market share. Based on Schoger (ibid.) and van Agten (2013:8)'s analysis, Apple's market share in terms of revenue fell from $81 \%$ in November 2012 to $63 \%$ in November 2013. At the same time, Google's market share rose from $19 \%$ in November 2012 to $37 \%$ in November 2013. Japan and South Korea stores were reported to be the biggest contributors to Google Play's increase in revenue. App developers would be well advised to develop Android versions of their best-selling dictionaries within the next year to ensure they do not miss out on revenue, particularly if the target countries are Japan and Korea.

\section{Value of dictionary app market}

Although the total daily revenue of Google Play and the Apple app store is $\$ 12$ and $\$ 18$ million, respectively, dictionary apps account for a mere $0.33-1.21 \%$ of the Apple app store revenue and $0.22-0.93 \%$ of Google Play revenue. ${ }^{1}$ The USA falls at the bottom of the range for both app stores, then the UK, Canada and Australia. Most sales of dictionaries apps are for learners of English and so the residents of English speaking countries have little need for bilingual dictionary apps at least. In contrast, the Japanese, South Korean and Germany stores show the highest revenues for dictionary apps indicating that residents of these countries are willing to spend significant amounts of money on good quality dictionaries. Tables 1 and 2 below

\footnotetext{
1 These percentages are based on Spriensma's (2012: “Downloads \& Revenues Per Category") findings that "books and references" make up $2 \%$ of Google Play and Apple App Store revenue. $2 \%$ is then multiplied by the minimum and maximum proportion of dictionary apps among the top 100 grossing reference apps shown in Tables 1 and 2 .
} 
Table 1 Number of dictionary apps in the top 100 grossing "Reference" category apps in the Apple App Store (iPhone) listed by store country (source: App Annie Store Stats: Top charts)

\begin{tabular}{lllll}
\hline Store country & 02-Nov-13 & 10-Nov-13 & 20-Nov-13 & Average \\
\hline Japan & 69 & 60 & 53 & 61 \\
South Korea & 50 & 62 & 58 & 57 \\
Germany & 33 & 42 & 43 & 39 \\
Italy & 36 & 40 & 34 & 37 \\
Russia & 38 & 37 & 33 & 36 \\
France & 33 & 30 & 30 & 31 \\
Australia & 29 & 25 & 31 & 28 \\
UK & 23 & 29 & 23 & 25 \\
Canada & 19 & 25 & 25 & 23 \\
China & 22 & 21 & 23 & 22 \\
USA & 16 & 14 & 20 & 17 \\
\hline
\end{tabular}

Table 2 Number of dictionary apps in the top 100 grossing "Books and Reference" category apps in Google Play listed by store country (source: App Annie Store Stats: Top Charts)

\begin{tabular}{lllll}
\hline Store country & 02 -Nov-13 & 10-Nov-13 & 20-Nov-13 & Average \\
\hline Japan & 50 & 48 & 41 & 46 \\
Germany & 34 & 34 & 37 & 35 \\
South Korea & 33 & 33 & 29 & 32 \\
Russia & 26 & 27 & 30 & 28 \\
France & 24 & 26 & 29 & 26 \\
Italy & 27 & 20 & 24 & 24 \\
UK & 21 & 23 & 21 & 22 \\
Australia & 24 & 23 & 18 & 22 \\
Canada & 19 & 19 & 23 & 20 \\
USA & 11 & 11 & 11 & 11 \\
\hline
\end{tabular}

show the proportion of dictionary apps making up the top 100 grossing apps in the 'Reference' category for each country.

It is not possible to calculate the total revenue of dictionary apps in the two app stores in absolute terms, as the figures given in Schoger (ibid.) are only for the top grossing 200 apps overall. No dictionary apps were found in the overall top 200 grossing apps on the Japan, China, South Korea, UK, France, Germany, Italy, Australia, Canada and US stores on the 2nd, 10th or 20th November 2013 (App Annie Store Stats: Top Charts). App dictionary publishers should therefore not expect profit winners in the same league as games, productivity and utility apps.

\section{Number of free and paid dictionary apps}

A comparison of the Apple App Store, Google Play and Amazon app stores using App Annie's Store Stats: App Database reveals that although the number of 
Table 3 Number of dictionary apps in Apple App Store and Google Play stores on 9th May 2013

\begin{tabular}{lclc}
\hline Price (USD) & Number of apps on Apple App Store & Price (USD) & Number of apps in Google Play \\
\hline$\$ 0.00$ & 773 & $\$ 0.00$ & 2,018 \\
$\$ 0.99$ & 633 & $\$ 0.01-\$ 0.99$ & 71 \\
$\$ 1.99$ & 374 & $\$ 1.00-\$ 1.99$ & 323 \\
$\$ 2.99$ & 303 & $\$ 2.00-\$ 2.99$ & 885 \\
$\$ 3.00-\$ 4.99$ & 1,684 & $\$ 3.00-\$ 4.99$ & 283 \\
$\$ 5.00-\$ 9.99$ & 743 & $\$ 5.00-\$ 9.99$ & 305 \\
$\$ 10.00-$ & 787 & $\$ 10.00-$ & 194 \\
$\$ 19.99$ & & $\$ 19.99$ & \\
$\$ 20.00-$ & 319 & $\$ 20.00-$ & 76 \\
$\$ 49.99$ & & $\$ 49.99$ & \\
$\$ 50.00-$ & 30 & $\$ 50.00-$ & 23 \\
Total & 5,646 & Total & 4,178 \\
Total paid & 4,873 & Total paid & 2,160 \\
Total $\geq \$ 10$ & 1,136 & Total $\geq \$ 10$ & 293 \\
\hline
\end{tabular}

dictionary apps available on Google Play is as high as $75 \%$ of the number on the Apple App Store, over $93 \%$ of Google Play's dictionaries apps are unbranded and cheap (under \$10). In contrast, $20 \%$ of dictionary apps on the Apple App Store are over $\$ 10$ and contain for the large part premium dictionaries.

On the 9th June 2013, the Apple App Store had 5,646 free and paid dictionary apps and Google Play 4,178 apps, giving a ratio of 57:43, respectively. If paid apps are solely considered, the number of apps drops to 4,873 and 2,160, respectively, i.e., a ratio of 69:31. Hence, although, Google's dictionary app numbers approach that of the Apple App Store, half of its apps are free and hence bring the developer little financial benefit. The exact price breakdown is given in Table 3 below.

If only apps costing $\$ 10$ or more are considered, then the app number ratio changes to 79:21, respectively. Only $7 \%$ of Google Play's dictionary apps are $\$ 10$ or over and hence most Android dictionaries are cheap and unbranded. $20 \%$ of the Apple App Store's apps, in contrast, are $\$ 10$ or over. These apps mostly contain premium, branded dictionaries which tend to sell well.

\section{Pricing of dictionary apps}

A review of dictionary app prices on the Apple App Store and Google Play in November 2013 reveals that the price of paid dictionary apps by well-known dictionary publishers was found to vary between approximately USD $\$ 3$ and USD $\$ 35$. The prices in the Japan store are significantly higher, on average, and several exceed $\$ 100$.

Generally speaking, app prices which are set by the dictionary publisher increase with the number of headwords in the dictionary-a tradition inherited from the print industry. A mini dictionary costs, for example, approximately $\$ 5$, whereas an 
unabridged dictionary costs on average between $\$ 20$ and $\$ 35$ dollars. Pocket and concise dictionaries are normally priced between $\$ 10$ and $\$ 20$ dollars.

Prices set by software developers, conversely, are often unrelated to the size of the dictionary. Unlike a book, users cannot determine from the app how many headwords it contains and so developers do not feel obliged to set the price based on the number of headwords. Some developers omit the word "pocket", "concise" etc. from the app name to conceal the dictionary size and lump the number of headwords, subentries, translations, phrases in a single large figure in the app description. Such developers may keep increasing the price until profit starts to fall. In some cases, these results in pocket size dictionaries being sold for over $\$ 30$, a price normally set for unabridged dictionaries.

\section{Language coverage}

The main publishing houses of Western European languages, Japanese and Korean have released apps for most of their dictionary range including separate apps for different sized dictionaries, e.g., mini, pocket, concise and unabridged. Although there are dictionary apps for other languages, e.g., Chinese, Arabic, Vietnamese, Thai, Polish, few if any are from the main dictionary publishing houses of that language and often only a limited range of dictionary sizes is covered.

\section{Characteristics of high-grossing apps}

It is possible to make generalizations about which kinds of dictionary apps rank highly in the grossing charts based on the rankings of dictionary apps between the years 2011 and 2013. The app revenues tend to be highest for well-known dictionary publishers in their own country, e.g., the PONS dictionaries by the German publisher PONS GmbH sell well in Germany. The Genius brand of EnglishJapanese dictionaries by Taishukan sells well in Japan. The Larousse French dictionaries sell very well in France. The rankings outside of their home country are generally much lower than in the home country. This is presumably because most learners of a particular language reside in their home country and use the dictionary compiled by well-known local publishing houses. For instance, most users of a French-English dictionary are French living in France and use dictionaries published by Larousse.

The exception to this generalization covers English dictionaries compiled by publishers such as Oxford University Press, Collins and Merriam-Webster. These dictionaries sell well outside the home countries of UK and USA, as many nonEnglish native speakers buy English monolingual dictionaries in their home country. Also noteworthy is that English leaner's dictionaries such as the Collins Cobuild Advanced Dictionary of English and Oxford Advanced Learner's Dictionary by Oxford University Press tend to sell best in the Far East and South East Asia.

As the highest grossing dictionary apps tend to be dictionaries by local publishers for the local language, one can conclude that the reputation of the publisher is the 
most significant factor in predicting the sales of a dictionary, not the functions of the dictionary or the reputation of the developer. Apps of well-known dictionaries offering basic headword search without advanced or extra features such as word quizzes, word games, the ability to search for examples, idioms and other inflectional forms of a word or phrase, are likely to sell just as well as a comparable dictionary app with these features. The French-English Dictionary by Larousse and the Merriam-Webster dictionary app are good examples of apps with no-frills features which sell very well.

There are, however, several examples of less known dictionaries becoming the best-selling apps in their country primarily because they were the first dictionaries available for that language, i.e., the first mover advantage. For example, although Genius is one of the best-selling English-Japanese print dictionaries, the Wisdom English-Japanese Dictionary app by Monokakido (www.monokakido.jp) is consistently ranked higher. Although Daijirin by the publisher Sanseido is not the bestknown Japanese monolingual dictionary, the app produced by Monokakido was one of the first to appear in the Apple App Store and is the most popular monolingual dictionary app. In addition, the design of its user interface won it great exposure from Apple. A third example of an early mover is the Chinese dictionary PLECO (www.pleco.com), which consistently ranks as the best-selling Chinese dictionary. The features of the app are specially geared toward learners of Chinese, who are willing to spend $\$ 5-\$ 15$ on in-app purchases such as hand-writing recognition, flash cards, optical character recognition and Chinese fonts.

\section{Freemiums and in-app purchases}

Over the last 2 years, a trend has evolved in which developers, particularly sellers of games, provide an app free of charge or at a very low price and offer premium content by way of in-app purchases. Such free apps are called freemiums. According to Schoger (2013), $92 \%$ of all revenue in the Apple app store and $98 \%$ in Google Play in November 2013 was generated through in-app purchases in free apps.

Freemiums are, however, poorly represented among dictionary apps. Although $77 \%$ of the revenue of apps categorized as 'Reference and Books' on the global Apple App Store are from freemium apps, $22 \%$ from paid apps and $2 \%$ from paid apps with in-app purchases (ibid.), on reviewing several hundred dictionary apps, only sixteen apps were found to offer in-app purchases. ${ }^{2}$ Cheap apps with in-app purchases or freemiums often only contain small, sometimes open source dictionaries to whet the appetite of users. Expensive apps with in-app purchase, however, normally contain a premium dictionary in the base app.

In-app purchases available in these apps include: branded general and specialized dictionaries, pricey tools for learning Chinese characters (PLECO-www.pleco.com),

\footnotetext{
${ }^{2}$ PLECO, ABBYY Dictionaries, Youdao, Ryusys, iCED, CamDictionary, アクセス独和辞典, コトバ ンク - 国語辞典, Hebrew Dictionaries by PROLOG, Ultralingua Dictionary Bookshelf, Daijisen Jpn-Jpn Dictionary, wishoTouch, World Dictionary, Dictionary.com, デ辞蔵, プログレッシブ英和・和英辞典 and DioDict contain in-app purchases.
} 
removal of banner ads (iCED-http://www.murage.ca/products/iced), addition of an unlimited number of words to one's personal vocab list (iCED), text-to-speech engine which allows the app to pronounce words and sentences (DioDictwww.diodict.com), voice recognition input (Dictionary.com, wishoTouch-sazanamisoftware.com), OCR for recognizing Chinese characters (wishoTouch, PLECO). The Prolog (www.prologhebrew.us), Ultralingua (www.ultralingua.com) and Langenscheidt Dictionaries (http://www.langenscheidt.de) apps are unique in that they are a single app containing trial versions of all the developers' dictionary apps. The full version of each dictionary can be activated with an in-app purchase.

The reluctance of dictionary app developers to make use of the freemium model is presumably due to the tradition in the print industry where a single book is the basic product. As print dictionary publishers are the ones to license their content to developers and drive dictionary app development in general, they carry this tradition on into the app store where one app is created for one print dictionary.

Ideally, several books or sources useful for learning a particular language should be integrated into one app. For example, the basic app may contain a general dictionary. Specialized dictionaries, a collocations dictionary, extra example sentences, phrase books, grammar and usage references, verb conjugation tables, pronunciation recordings and cultural notes could be made available as in-app purchases. The Chinese dictionary app PLECO offers many in-app purchases containing aids for learning Chinese characters. This contributes to its consistent highest rankings among Chinese dictionaries across stores.

\section{Competitors of dictionary apps}

The biggest competitors of paid dictionary apps fall into three categories: (1) machine translation engines, (2) portals and websites offering free premium dictionary content and (3) dictionaries embedded in mobile phone operating systems.

Machine translation apps allow users to translate single words or entire sentences automatically. They are popular as they are mostly free, allow translation between a large combination of languages, support sentence input using voice recognition and can pronounce the output sentence using speech synthesis technology. Examples of machine translation apps are Google Translate, Naver Translate App, GenieTalk and S-Translator, which is pre-installed on Samsung's Galaxy S4 phone.

High-quality machine translation apps show a high user satisfaction rating and hence are an important competitor of dictionary apps. On the 6th January 2014, 22,189 people in the USA Apple app store had given Google Translate an average rating of 31/2 out of 5 (iTunes Preview: Google Translate). 731,579 users of Google Play had given the app a rating of 4.5 out of 5 (Google Play: Google Translate).

The second main competitor of dictionary apps consists of Internet portals and publisher websites that provide free access to premium dictionaries. PONS, Larousse, Collins and Oxford University Press dictionaries can be browsed free of charge on the publishers' websites. Publishing companies presumably allow their dictionaries to be browsed for free, as they would rather general search engines such 
as Google display their dictionary's definitions in the search results than the definitions from the many unbranded dictionaries available on the Internet.

There are also Internet portals such as Naver (dic.naver.com), Yahoo Japan (dic. yahoo.co.jp), Dictionary.com (dictionary.reference.com) and Yandex (slovari.yandex.ru) which provide a large number of high-quality dictionaries licensed from reputable dictionary publishers free of charge on their website. These portals generate income by selling advertising space and the premium dictionary content increases traffic and hence their website's exposure.

The prime advantage of using a dedicated dictionary app compared to visiting a web portal with dictionaries was originally that the app was much faster, more complex animation sequences could be shown, and buttons could be provided to pronounce words and sentences. With the introduction of ultra-fast LTE networks and the promulgation of HTML5-a website language which allows developers to implement animation, sound and video into websites more easily, the difference in user experience between a dedicated dictionary app and a dictionary website viewed in a standard browser is fast diminishing. The only major advantage now is that dedicated dictionary apps allow access to the dictionary when there is no Internet connection.

The last competitor of dictionary apps are dictionaries embedded in the operating system of smartphones and e-readers. After clicking on a word in an iPhone or iPad with iOS 7 installed and selecting "Define", matching entries from English, French, Spanish, Italian, German, Korean, Japanese and Chinese monolingual dictionaries and English-Korean/Chinese/Japanese bilingual dictionaries are displayed.

\section{Conclusion}

After reading the above description of dictionary app revenue models, the market share of app stores, the differences in dictionary apps between app stores, app pricing strategies and the competitors of dictionary apps, readers should now have a good overview of the dictionary app market.

The future of dictionary apps as money earners is, however, bleak, as more and more portals are providing free access to premium dictionaries, more and more device manufacturers are embedding dictionaries in their operating systems for free and finally the quality of machine translation software is fast approaching that of dictionaries. In future, users will no longer need to spend money on a dictionary app, as good quality translations with additional examples and translation guides will be available free of charge in the Internet.

Instead, publishers should go beyond creating one app for one dictionary and create a product which integrates all content a language learner might need. Dictionary content, grammar reference works, vocab trainers, phrasebooks for travelers, encyclopedic content, culture guides, native speaker pronunciation of words and sentences, language proficient exam mock questions as well as general language exercises should be combined into a single application where relevant information is interlinked. In this way, language learners would no longer to search in various sources to learn a language. Such a product would go beyond what 
machine translation and portal sites can easily offer. They could also be marketed to the more profitable B2B sector such as schools, companies and government for inhouse language education or writing skills.

\section{References}

App annie store stats: App database. http://www.appannie.com/search/. Accessed 9th June 2013.

App annie store stats: Top charts. http://www.appannie.com/top/. Accessed 30th December 2014.

iTunes Preview: Google Translate. https://itunes.apple.com/en/app/google-translate/id414706506?mt=8. Accessed 6th January 2014.

Google Play: Google Translate. https://play.google.com/store/apps/details?id=com.google.android.apps. translate. Accessed 6th January 2014.

Schoger, C. 2013. 2013 Year in review. Distimo Publication. http://www.distimo.com/download/ publication/current. Accessed 31st December 2013.

Spriensma, G. J. 2012. 2012 Year in review. Distimo Publication. http://www.distimo.com/publications/ archive/Distimo\%20Publication\%20-\%20Full\%20Year\%202012.pdf. Accessed 9 June 2013.

van Agten, T. 2013. May 2013: A Granular app level look at revenues. Distimo Publication. http://www.distimo.com/publications. Accessed 9 June 2013. 